experimental dish-pan type flow actually carry over to the atmosphere, in which the heat sources are to some extent different? (One serious drawback of theoretical attempts up to the present is that the vertical temperature gradient is prescribed initially and is not a product of the solution of the equations.) The processes of momentum transfer in the experimental work and in the atmosphere are now fairly fully understood; energy transfer processes are also understood and Dr. Sutcliffe's results may be summed up by saying that the presence of water vapour in the energy-transfer problems alters the tempo rather than changes the pattern.

So far as the planets are concerned, Prof. Urey's work demonstrates that chemical composition has to be brought in in building up the complete picture of the general circulation. Dr. Goody has made it quite clear that the large-scale dynamical problems for the atmosphere of Mars may be much simpler for meteorologists than our own atmosphere, due to the fact that its water vapour content is so much less. In the case of Jupiter, where there is a variation of the mixing ratio with height, it is possible for there to be one atmosphere overlying another with little or no interaction, and this raises quite difficult problems of interpretation.

T. V. Davies

\section{THE EUGENICS SOCIETY}

$\mathrm{O}^{\mathrm{N}}$ $\mathrm{N}$ December 4 the Eugenics Society held a dinner under the presidency of Sir Charles Galton Darwin, in celebration of its first fifty years of active life. The jubilee dinnor was the occasion of two special events. The first was the presentation of the Galton Medal to Dr. C. P. Blacker. This Medal, a mark of high distinction and esteem, is the highest honour in the gift of the Society. It has been awarded on a single previous occasion, a dozen years ago, to Sir Alexander Carr-Saunders, later to be president of the Society, who was present and spoke at the dinner.

Dr. Blacker, now honorary secretary of the Society, was its general secretary for the twenty-one years during 1931-52, so spanning the presidencies of Sir Bernard Mallet, Sir Humphry Rolleston, Lord Horder and Sir Alexander Carr-Saunders.

The presentation of this rare award is testimony to Dr. Blacker's great knowledge, zeal and vigour on behalf of the Society. It is very largely through his writings and influence that the Society has been able to lead public opinion in a controversial field and age.

The second special feature of the jubilee was the issue of the Society's revised Statement of Aims. This document, as well as treating of eugenic science, studies and policies, provides an impressive list of the past activities of the Society. They afford a convincing indication of the way in which the Society has often been able to lead-albeit quietly and by stimulation in the right quarters at the right time. Possessing freedom, by the good fortune of endowment, the Society has been able to initiate and catalyse chosen efforts and researches, frequently doing so by help to cognate societies, such as the International Planned Parenthood Federation, tho Family Planning Association, the British Social Biology Council, and others.

Prominent among the Society's activities pursued by such means have been Lidbetter's classic researches on the social problem group, and later work on problem families; Baker's work in the 'thirties on the elaboration and testing of chemical spermicides as a stage in the improvement of contraceptives without which appropriate differential fertility cannot be brought about; Lewis's work on morbid inheritance; and the Population Investigation Committee (of which Carr-Saunders and Blacker were joint founders), which was the forerunner of the Royal Commission on the Population of Great Britain. Further, there have been two especially close collaborations with Political and Economic Planning on population policy for Great Britain a decade and more ago, and much more recently on world population and resources. An inquiry into promising families will soon be published.

The Society's journal, the Eugenics Review, has been published as a quarterly since 1909, and following the Second World War there has been issued additionally a series of important occasional papers by Blacker, Burt, Thomson, Terman and others.

The Society's jubileo also coincides with a change in the general secretaryship. Dr. C. O. Carter, who succeeded Dr. Blacker in 1952, has now joined the Medical Research Council Clinical Genetics Research Unit at the Hospital for Sick Children, Great Ormond Street. His place has been taken by Dr. G. C. L. Bertram who, after seven years as director of the Scott Polar Research Institute in Cambridge, has recently spent a period in New Zealand as William Evans visiting professor in the University of Otago.

The aims of the Society may be summarized as being: to study the influences which may modify inborn human qualities; to formulate and support policies for developing these qualities to the utmost advantage ; to promote research on eugenic problems ; to foster a responsible attitude to parenthood ; and to guide public opinion in these matters.

The Society's address is 69 Eccleston Square, S.W.1.

\section{WORK STUDY}

N the four years of its existence the European Productivity Agency has done much to stimulate increased productivity in industry through conferences, courses, visits of consultants, publications and other means. Some of its activities have been of little value to progressive organizations and have been unnoticed and unheeded by others. In the main, however, the Agency has provided a most valuable service in acting both as a stimulant and as a medium for promoting exchange of useful ideas and methods between firms in the participating countries. The majority of its reports have been welcomed by those looking for new ideas and tech. niques to increase productivity.

Of all the reports the Agency has produced, "Labour Management on the Farm"* will almost certainly be regarded as one of the most valuable. It contains information which has been culled from innumerable sources and which has never appeared before in one volume. It is of direct and practical value to the thinking farmer who is prepared to revise his methods to improve his efficiency; it has been carefully planned and well written.

The report owes its genesis to a seminar organized on behalf of the European Productivity Agency by

* "Labour Management on the Farm". Pp. 171. (Paris: European Productivity Agency of the Organization for European Co-operation, 